\title{
ANTIMICRobial ACTIVITY of GluCOPRotamin: A Clinical Study of a New Disinfectant for INSTRUMENTS
}

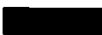 \\ Andreas F. Widmer, MD, MS; Reno Frei, MD, FAMH
}

\begin{abstract}
OBJECTIVE: To determine the in vitro efficacy of glucoprotamin for the disinfection of instruments.

DESIGN: Prospective observational study.

SETTING: University women's hospital.

METHODS: Instruments were immersed in saline solution after use, and glucoprotamin was added to a concentration of $1.5 \%$ before soaking for 60 minutes. Biocidal activity was determined by the difference in colony-forming units (CFU) on instruments before and after disinfection.
\end{abstract}

RESULTS: One hundred thirty-seven instruments were col- lected during 10 days and exposed to a $1.5 \%$ dilution of glucoprotamin without prior washing. Bioburden before disinfection ranged from 2 $\times 10^{5}$ to $7.1 \times 10^{7} \mathrm{CFU}$ per instrument. Average bacterial killing was $5.98 \log _{10} \mathrm{CFU} \pm 0.48$ under aerobic conditions and $6.75 \log _{10} \mathrm{CFU} \pm$ 0.54 under anaerobic conditions, despite the presence of large amounts of proteins on instruments that were frequently bloody. No vegetative bacteria were isolated in any sample after disinfection.

CONCLUSION: This clinical study confirmed excellent in vitro efficacy of glucoprotamin without prior removal of proteins and debris (Infect Control Hosp Epidemiol 2003;24:762-764).
Semicritical devices must undergo reliable disinfection and preferably sterilization before reuse. ${ }^{1}$ Aldehydes and phenolic agents are the preferred disinfectants for surgical instruments. Phenolics have excellent detergent properties in addition to antimicrobial efficacy. They clean, dissolve proteins, and disinfect in one step. However, phenolics have limited activity against organisms such as Pseudomonas aeruginosa ${ }^{2,3}$ and Aspergillus fumigatus. ${ }^{4}$ In addition, the residues of wasted phenolic agents raise environmental concerns. Glucoprotamin, a new disinfectant, is based on a conversion product of L-glutamic acid and $\operatorname{coco}\left(\mathrm{C}_{12 / 14}\right)$ alkylpropylene-1.3-diamine (Figure). ${ }^{1,5,6}$ It provides advantages similar to those of phenolics, but is significantly more active against bacteria and viruses. It is also environmentally safe.

Glucoprotamin is nonvolatile, easily dissolved in water, nonteratogenic, nonmutagenic, and easily degradable according to Organization for Economic Cooperation and Development guidelines, and has excellent toxicologic properties. It is active in vitro against vegetative bacteria including mycobacteria, fungi, and viruses. ${ }^{1,6}$ Undiluted glucoprotamin is also effective against bacterial spores. It is highly active against mycobacteria that are usually difficult to kill by disinfectants. In fact, some glutaraldehyderesistant strains of Mycobacterium chelonae were efficiently killed by glucoprotamin but not by other disinfecting agents. ${ }^{7}$ Glucoprotamin is licensed in Europe as a highlevel disinfectant for instruments and has, in part, replaced the use of phenolics and aldehydes. In contrast to aldehydes, glucoprotamin dilutions being used have limited activity against bacterial spores. Glucoprotamin is noncorrosive to metals and compatible with most materials used in healthcare. The recent crisis in Europe involving Creutzfeldt-Jakob disease and its new variant promoted the use of disinfectants not based on aldehyde. The active group of aldehydes (eg, the carbonylic group) binds to the amino groups of proteins and may impede the removal of prion proteins from surgical instruments. Several in vitro and experimental in vivo studies have been performed on glucoprotamin and published mainly in the non-English literature. However, there are no published studies of the inhospital use of glucoprotamin.

\section{METHODS}

Sekusept Plus (Ecolab, Duesseldorf, Germany) contains $25 \mathrm{~g}$ of glucoprotamin in $100 \mathrm{~g}$ of disinfectant concentrate, nonionic detergents, solvents, complexing agent, corrosion inhibitors, color, and fragrance. We tested the antimicrobial activity of this product against the germs contaminating clinically used instruments from a women's hospital. Used specula and forceps were collected, placed in sterile plastic bags, and sent to the laboratory within 1 hour. Collection was performed during 10 consecutive days, with 


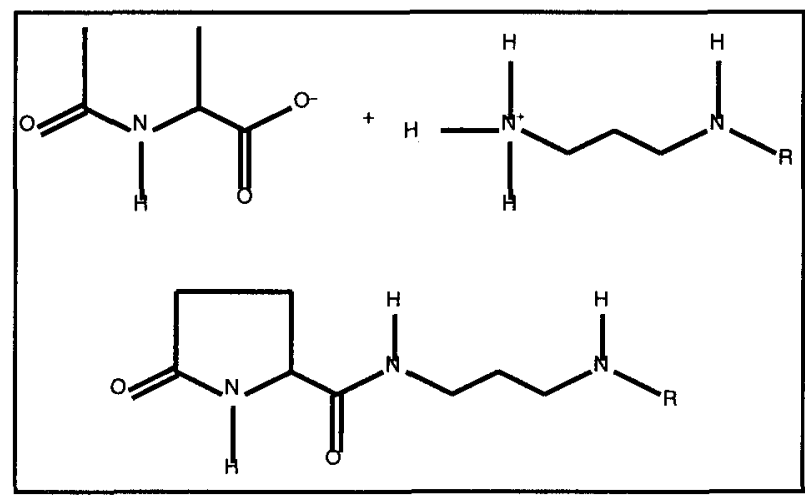

FIGURE. Chemical structure of glucoprotamin $\left(\mathrm{R}=\mathrm{C}_{12 / 14} \mathrm{H}_{25 / 29}\right)$.

a mean of 7 specula and 6 forceps per day. Instruments were collected at noon, not later than 4 hours after use, and processed in the afternoon of the same day. No washing or cleaning procedure was allowed to be performed on these instruments. In the laboratory, instruments were immersed in $5 \mathrm{~L}$ of $0.9 \% \mathrm{NaCl}$. One milliliter of the solution was used to determine the bacterial density before the disinfection process. Plates with serial dilutions of $1: 10,1: 100$, and 1:1,000 were incubated under aerobic and anaerobic conditions. Immersed instruments were exposed by adding glucoprotamin (Sekusept Plus) to a final concentration of $1.5 \%$ before soaking for 60 minutes. After filtration of a $500-\mathrm{mL}$ aliquot, membranes $(0.45-\mu \mathrm{m}$ pores) were rinsed with $500 \mathrm{~mL}$ of neutralizer, followed by $0.9 \% \mathrm{NaCl}(500 \mathrm{~mL})$. The membranes were incubated on blood agar for 48 hours at $35^{\circ} \mathrm{C}$.

The disinfection activity was measured as a reduction factor determined by calculating the difference in $\log _{10}$ colony-forming units (CFU) before and after disinfection. The optimal concentration of the neutralizing agent ( $1 \%$ polysorbate $80,0.3 \%$ lecithin, $0.1 \%$ histidine, and $0.1 \%$ cysteine in $0.1 \mathrm{M}$ of phosphate buffer at $\mathrm{pH} 7.4$ ) was determined by serial dilution experiments.

\section{RESULTS}

A total of 137 instruments were studied: 73 specula and 64 forceps. All samples were included in the results. Instruments were visibly soiled with secretions, detritus, and blood before being immersed in the disinfection solution. The average bioburden per instrument used in the women's hospital was high, between $10^{5}$ and $10^{7} \mathrm{CFU}$ per instrument (Table). Bacterial killing was more than 5 $\log _{10}$ CFU (range, 5.01 to 7.17 ), even in the presence of large amounts of proteins (Table). No vegetative bacteria were isolated after the disinfection process. As expected from the in vitro tests, bacterial spores (mainly Bacillus and Clostridium species) remained viable in all samples after the disinfection process. However, bacterial density averaged less than $0.02 \mathrm{CFU} / \mathrm{mL}$. To further analyze the effectiveness of glucoprotamin against $C$. difficile, a suspension test was performed. Glucoprotamin reduced $C$. difficile by $3 \log _{10}$ CFU or more.
TABLE

Bioburden and Reduction Factors Against Vegetative BaCteria OBTAINED From THE InSTRUMENTS

\begin{tabular}{llc}
\hline $\begin{array}{l}\text { Type of } \\
\text { Incubation }\end{array}$ & $\begin{array}{c}\text { Mean } \\
\text { Bloburden* }\end{array}$ & $\begin{array}{c}\text { Mean Reduction } \\
\text { Factors After } \\
\text { Exposure to } \\
\text { Glucoprotamin* }\end{array}$ \\
\hline Aerobic & $6.73 \log _{10} \pm 0.54$ & $5.98 \log _{10} \pm 0.48$ \\
Anaerobic & $7.18 \log _{10} \pm 0.15$ & $6.75 \log _{10} \pm 0.54$ \\
\hline
\end{tabular}

*Colony-forming units per instrument \pm standard deviation.

\section{DISCUSSION}

Glucoprotamin is the first new disinfectant to emerge in decades. In this clinical trial, we confirmed the in vitro efficacy of glucoprotamin against bacteria on instruments after use in a women's hospital. Bacterial killing of more than $5 \log _{10}$ CFU was observed after 1 hour, although the instruments were not washed before the disinfection process. This first step of decontamination was omitted for study purposes to challenge the action of glucoprotamin to kill microorganisms in the presence of large volumes of proteins. Bacteria on contaminated surfaces are up to 300 -fold more resistant to disinfectants than are those in suspension. ${ }^{3}$ Therefore, results from in vitro studies should be confirmed with data resembling clinical use or preferably in a clinical study. Neither phenolics nor glucoprotamin have a claim for sporicidal activity. However, preliminary data suggest that glucoprotamin is more active against spores than are phenolics. Glucoprotamin is licensed in Europe as a disinfectant for instruments and endoscopes. Despite being nonteratogenic, nonmutagenic, and safe as an in-use solution, glucoprotamin in the concentrated form requires care and the use of personal protective equipment during handling, similar to other disinfectant concentrates.

Several limitations of this study must be acknowledged. First, we did not quantify the extent of proteins on the instruments. However, the large number of samples tested on different days and the fact that these instruments came from a general women's clinic suggest that the level of contamination was likely to be representative. Second, we did not use cultures for mycobacteria on the instruments. Therefore, surface-bound mycobacteria may not be rapidly killed under these conditions. However, glucoprotamin is significantly more active against atypical mycobacteria than is glutaraldehyde. ${ }^{6}$ Glucoprotamin is registered in Europe for reprocessing endoscopes, where mycobacteria is a serious problem. ${ }^{7,8}$ In contrast to aldehydes, mycobacteria that are resistant to glucoprotamin have not yet been observed. Spores are not killed at the concentration and exposure time studied. However, the goal of high-level disinfection is to eliminate all vegetative bacteria including mycobacteria. ${ }^{1}$ Few disinfectants have been registered by the Food and Drug Administration as 
sterilants (ie, compounds shown to reliably kill bacterial spores). The instruments in this study had come into contact with mucous membranes only, and did not belong to the class of critical instruments. ${ }^{9}$ More than $3 \log _{10}$ CFU of C. difficile were killed in a suspension test. Glucoprotamin is not registered as an active compound against spores. However, it is still fairly active against one of the clinically important spores, as indicated by our tests against $C$. difficile. This activity was much better than that of phenolics.

We studied glucoprotamin, a new disinfectant, under clinical conditions. The excellent results despite the lack of washing to eliminate debris and proteins confirm those of prior in vitro studies.

\section{REFERENCES}

1. Widmer AF, Frei R. Decontamination, disinfection, and sterilization. In: Murray PR, Baron EJ, Pfaller M, Jorgensen JH, Yolken R, eds.
Manual of Clinical Microbiology, 8th ed. Washington, DC: American Society of Microbiology Press; 2003:77-108.

2. Rutala WA. Cole EC. Ineffectiveness of hospital disinfectants against bacteria: a collaborative study. Infect Control 1987;8:501-506.

3. Sagripanti JL, Bonifacino A. Resistance of Pseudomonas aeruginosa to liquid disinfectants on contaminated surfaces before formation of biofilms. J AOAC Int 2000;83:1415-1422.

4. Terleckyj B, Axler DA. Quantitative neutralization assay of fungicidal activity of disinfectants. Antimicrob Agents Chemother 1987;31:794-798.

5. Disch K. Glucoprotamine: a new antimicrobial substance. Zentralbl Hyg Unweltmed 1994;196:357-365.

6. Meyer B, Kluin C. Efficacy of glucoprotamin containing disinfectants against different species of atypical mycobacteria. I Hosp Infect 1999;42:151-154.

7. Van Klingeren B, Pullen $\mathrm{W}$. Glutaraldehyde resistant mycobacteria from endoscope washers. I Hosp Infect 1993;25:147-149.

8. Griffiths PA, Babb JR, Bradley CR, Fraise AP. Glutaraldehyde-resistant Mycobacterium chelonae from endoscope washer disinfectors. $J A p p l$ Microbiol 1997;82:519-526.

9. Spaulding EH. Chemical disinfection of medical and surgical materials. In: Block S, ed. Disinfection, Sterilization and Preservation. Philadelphia: Lea \& Febiger; 1968:517-531. 